\section{Public Health Genomics}

Public Health Genomics 2012;15:22-30

DOI: $\underline{10.1159 / 000327296}$
Received: July 6, 2010

Accepted after revision: March 9, 2011

Published online: June 3, 2011

\title{
Motivations and Perceptions of Early Adopters of Personalized Genomics: Perspectives from Research Participants
}

\author{
S.E. Gollust ${ }^{a}$ E.S. Gordon ${ }^{b}$ C. Zayac ${ }^{c}$ G. Griffin ${ }^{c}$ M.F. Christman ${ }^{b}$ \\ R.E. Pyeritz ${ }^{c, d} \quad$ L. Wawak ${ }^{b}$ B.A. Bernhardt ${ }^{c}$ \\ aDivision of Health Policy and Management, University of Minnesota School of Public Health, Minneapolis, Minn.; \\ bThe Coriell Institute for Medical Research, Camden, N.J.; 'Penn Center for the Integration of Genetic Healthcare \\ Technologies, Division of Medical Genetics, and d Leonard Davis Institute of Health Economics, University of \\ Pennsylvania, Philadelphia, Pa., USA
}

\section{Key Words \\ Commercialization $\cdot$ Consumer views $\cdot$ Genetic tests • \\ Direct-to-consumer $\cdot$ Personalized medicine $\cdot$ Public expectations - Survey research}

\begin{abstract}
Background/Aims: To predict the potential public health impact of personal genomics, empirical research on public perceptions of these services is needed. In this study, 'early adopters' of personal genomics were surveyed to assess their motivations, perceptions and intentions. Methods: Participants were recruited from everyone who registered to attend an enrollment event for the Coriell Personalized Medicine Collaborative, a United States-based (Camden, N.J.) research study of the utility of personalized medicine, between March 31, 2009 and April 1, $2010(n=369)$. Participants completed an Internet-based survey about their motivations, awareness of personalized medicine, perceptions of study risks and benefits, and intentions to share results with health care providers. Results: Respondents were motivated to participate for their own curiosity and to find out their disease risk to improve their health. Fewer than $10 \%$ expressed deterministic perspectives about genetic risk, but $32 \%$ had
\end{abstract}

misperceptions about the research study or personal genomic testing. Most respondents perceived the study to have health-related benefits. Nearly all (92\%) intended to share their results with physicians, primarily to request specific medical recommendations. Conclusion: Early adopters of personal genomics are prospectively enthusiastic about using genomic profiling information to improve their health, in close consultation with their physicians. This suggests that early users (i.e. through direct-to-consumer companies or research) may follow up with the health care system. Further research should address whether intentions to seek care match actual behaviors.

Copyright $\odot 2011$ S. Karger AG, Basel

\section{Introduction}

The promise of personalized medicine is to integrate genomic information into medical care to offer individualized risk assessment, clinical screening, lifestyle change recommendations, and medications to reduce risk [1]. Personalized medicine has been launched into prominence by controversial direct-to-consumer (DTC) genetic testing companies offering consumers genetic-based

\section{KARGER}

(C) 2011 S. Karger AG, Basel

Fax +4161306 1234

E-Mail karger@karger.ch

www.karger.com
Accessible online at: www.karger.com/phg
Sarah E. Gollust, PhD

Division of Health Policy and Management

University of Minnesota School of Public Health

420 Delaware St SE, MMC \#729, Minneapolis, MN 55455 (USA)

Tel. +1 612626 2618, E-Mail sgollust@umn.edu 
risk information for common diseases and medication response $[2,3]$. While experts disagree over whether this type of genomic risk information has current value for disease prevention, most agree that scientific evidence of the impact of personal genomic information on behaviors and health outcomes is lacking [4-7]. As a result, leaders in the field recommend that empirical research be conducted to establish the impact of genomic risk information on health $[8,9]$ and to assess users' perceptions of the utility of personal genomics and their expectations of benefits and harms $[10,11]$.

In recent years, commentators have engaged in a lively debate over the promise and potential concerns of personal genomics as a new clinical tool. Some describe the pitfalls as the potentially limited scientific or clinical value of genomic profiling information, particularly the small relative risks genetic variants contribute (usually under 1.5 for common complex diseases), and the fact that currently identified variants, nearly all from genome-wide association studies of selected populations, explain only a small proportion of genetic contribution to disease [12]. Others point toward the limited existing evidence that genomic risk information motivates behavior changes to reduce individual disease risk, a key requirement for genomic information to improve health [13]. Commentators also raise concerns about the educational needs of consumers and providers [14], the potential for misunderstanding genetic risk information [6] and the adequacy of legal and regulatory oversight of genome profiling [15].

Though some of these issues are informed by evidence, others are still speculative. Overall, there has been little empirical research assessing users' response to genomic profiling for common chronic health conditions [7]. Nationally representative studies in the U.S. reveal little about the users of personal genomics; in one study, $22 \%$ of respondents were aware of DTC personal genomic tests, but only $0.3 \%$ had used them [16]. Thus, researchers have sought innovative ways to find likely early adopters of these services. According to Rogers' [17] classic theory of the diffusion of innovations, 'early adopters' are the second group to adopt a new technology (after the few truly exceptional novelty-seeking 'innovators'). Early adopters tend to be socially well connected, have higher education than average, have a strong capacity for coping with uncertainty, and possess favorable attitudes toward science. Applying this concept to the health care system, Berwick [18] suggests early adopters of health care innovations are likely to be particularly willing to engage in trials of new technolo- gies. Thus, in the case of users of personal genomic technologies, potential early adopters are likely to include individuals who utilize online social networks, are willing to volunteer for medical research related to new medical technologies and who are consumers of the latest gadgets and medical devices.

One study surveyed users of the social networking site Facebook about their attitudes toward personal genomics [19]. They found that $47 \%$ were aware of DTC genetic tests, significantly more than in the general population, but only $6 \%$ had used them [19]. Other researchers interested in a more in-depth understanding of users' motivations have either recruited participants directly to be screened for common variants [20] or recruited people who had already used a commercial genomic profiling service [21]. While these qualitative studies convey rich insight into users' understanding of and response to genomic profiling, small sample sizes (less than 25) and the scientific expertise of the participants involved [20] limit their generalizability. Two other recent studies have evaluated larger samples of consumers of DTC testing through online surveys $[22,23]$. These studies demonstrate that most consumers of these services use them to satisfy their curiosity and learn about their risks for disease [23], but that almost half of early users of DTC testing have concerns about the process or experience [22]. While these studies helpfully characterize the perceptions of those early adopters who have already undergone personal genomic testing, the fact that participants in both of these studies sought out testing independently and had to pay (albeit with varying cost sharing arrangements) for their testing out of pocket suggests that these samples may not be comparable to those who may encounter genomic testing in non-commercial, clinical settings. One final important research effort to evaluate personal genomic testing is the Multiplex Initiative, wherein a defined population of enrollees in a U.S. urban health system was offered the opportunity to get tested for a set of variants associated with 8 common health conditions [24]. In contrast to the Multiplex study population which was actively recruited from a sample of members of a health maintenance organization and compensated for their participation, we contribute to this growing body of 'early adopters' research by drawing from a self-selected population of people expressing interest in personalized medicine - volunteer participants in an ongoing research study, the Coriell Personalized Medicine Collaborative (CPMC).

The CPMC is a research study conducted by the Coriell Institute for Medical Research, with the goal of as- 
sessing the clinical utility of personalized risk information [25]. The CPMC collects participants' family history, medical history and lifestyle information; it performs genotyping for a select set of conditions (i.e. common diseases and variants predicting drug response), with no cost to participants. An advisory board determines which published replicated variants will be shared based on whether they are potentially 'medically actionable'. As of April 2010, the study released risk information for coronary artery disease, type 2 diabetes, hemochromatosis, prostate cancer, age-related macular degeneration, melanoma, and systemic lupus erythematosus. Unlike commercial DTC companies which provide risk estimates based solely on the presence or absence of selected genetic variants, the CPMC attempts to convey the multifactorial nature of common complex disease by providing participants with estimates of their relative risk for each condition due to family history and other clinical and behavioral indicators (e.g. smoking status and body mass index) in addition to their risk based on individual genetic variants. Participants receive their results via a secure web portal, and genetic counseling is made available to all participants at no charge.

Those interested in participating in the CPMC attend a group informed consent session where they hear an educational presentation about personalized medicine and details about the CPMC study, including the type of conditions that are reported, how participants are informed about results, the study requirements (medical history, family history and lifestyle questionnaires), and its limitations, risks, and benefits. At the conclusion of the session, they are given the opportunity to ask questions, and then they have the option to enroll by signing the informed consent form and submitting a saliva sample. CPMC participants must be 18 years or older and have a valid e-mail address. As of April 2010, 4,619 participants had enrolled in the CPMC.

In this study, participants and potential participants of the CPMC were surveyed to ascertain their (1) motivations for enrolling in the CPMC, (2) perceptions of the risks and benefits of the study, and (3) intentions to share their personalized risk results with their health care providers.

\section{Subjects and Methods}

Study participants were recruited from the population of people who registered to attend a CPMC enrollment event between March 31, 2009 and April 1, 2010. The CPMC recruits through a variety of mechanisms, including the project website (www.cpmc. coriell.org), word of mouth, media attention (local news articles), and through partner organizations including local hospitals and insurers. Recruitment at partner organizations has been limited to employees of those institutions through employee newsletters and e-mails with no access to customers, clients or patients who are not employees. The CPMC has not used any paid advertisements or advertisements (i.e. flyers) posted in public spaces. Everybody who registered for a CPMC enrollment event, thus expressing interest in personal genomics, was e-mailed an invitation to participate in this ancillary study along with a link to the secure web-based survey (hosted by SurveyMonkey.com) between 2448 hours after the scheduled event. The CPMC enrollment event consisted of a 45 minute presentation which included an explanation of personalized medicine, potential applications of personalized medicine, CPMC study design, and study requirements, together with risks, benefits and alternatives to participation. In addition, the presentation includes: (1) a discussion of health conditions currently included in the CPMC study, (2) pharmacogenomic tests and the medications they influence that are expected to be included in the future, and (3) examples of types of conditions that will not be included in the CPMC. Individuals were recruited regardless of whether they actually attended the enrollment event or decided to enroll in the CPMC study. The anonymous survey took fewer than 10 minutes to complete. All surveys were distributed and completed before respondents received any risk information, and there was no possibility of connecting respondents to their subsequent risk information.

Survey items were mainly closed-ended, but a few open-ended questions were included given the exploratory nature of this study. Measures were created de novo for this study based on review of relevant literature. The main measures included: motivations to participate in the CPMC study, measured on a 4-point Likert scale from not important to very important; awareness and prior use of personalized medicine and DTC genetic testing; perceptions of personal genomics and the risks and benefits of the CPMC study, measured on a 5-point Likert scale from strongly disagree to strongly agree; and dichotomous (yes/no) responses assessing participants' understanding of the CPMC study. Respondents were also asked if they intended to share their results with their health care providers, and why or why not. For all attitudinal questions, participants were offered an 'other' response to fill in; these respondent-generated responses were analyzed qualitatively. At the end of the survey, respondents answered demographic questions (age, gender, education, race/ethnicity, employment in a medical profession, self-rated health, and whether they have children).

Survey data analysis consisted of descriptive statistics (e.g. frequencies). Bivariate logistic regression and multivariate logistic regression models were estimated to assess how respondent characteristics relate to their perceptions of personal genomics. All analyses were conducted using Stata 10.1.

The study received human subjects approval from the Institutional Review Boards of the University of Pennsylvania and the Coriell Institute for Medical Research and informed consent (without signature documentation, given the requirement of anonymity for the Internet-based survey) was received from all participants. 


\section{Results}

Out of the 665 people invited to participate (all those who registered for a CPMC enrollment event over the one-year study period), 369 people agreed, for a response rate of $55.5 \%$. Respondents tended to be female, white, with high levels of education, and more than $40 \%$ worked in the medical profession or had a family member who did (table 1). This sample is representative of the overall CPMC population [21], and reflects the CPMC strategy of recruiting both in the community and in health care settings. Among all survey respondents, most (92.8\%) actually attended the enrollment event for which they registered; those that did not attend intended to reschedule. Nearly all respondents who attended an event (95.0\%) decided to enroll in the CPMC study.

Awareness of personal genomics was high, with $78 \%$ of respondents reporting hearing about personal genomics $(22.1 \%$ had never heard of personal genomics, $58.9 \%$ had heard a little, $18.9 \%$ had heard a lot). Only $14.7 \%$ reported ever visiting a web site for a DTC testing company; 7 individuals stated that they had previously purchased DTC genetic testing.

\section{Motivations to Participate}

Respondents indicated that curiosity, finding out about their disease risk and improving their health (table 2) were their most important motivations to participate in the CPMC, with over $75 \%$ of respondents reporting these as very important to their decision. Helping researchers and the fact that there was no cost to participate were also judged as very important factors by the majority of respondents. More than half were motivated to participate because they hoped to find out their risk for a particular condition. The most commonly cited conditions of interest included heart disease $(n=58)$, diabetes ( $\mathrm{n}=24)$ or cancer $(\mathrm{n}=22$ general cancer, $\mathrm{n}=25$ specific cancers), but 12 people indicated they wanted to know their risk of Alzheimer disease, despite the fact that it was described in the enrollment event as a disease that would not be included in the CPMC.

Write-in responses for other motivations to pursue personal genomic testing were generally consistent with those listed in table 2, touching on themes that the information was exciting, interesting or fulfilled their curiosity (e.g. 'It's an adventure!'), that the information would positively influence their health, or that they wanted information for their families or to fill in missing family history. Seven individuals attributed their motivation to a professional interest in learning more about personal
Table 1. Characteristics of respondents $(n=369)$

\begin{tabular}{|c|c|}
\hline Characteristic & $\%$ of total sample \\
\hline \multicolumn{2}{|l|}{ Age, years ${ }^{\mathrm{a}}$} \\
\hline $18-29$ & 12.5 \\
\hline $30-49$ & 27.3 \\
\hline $50-64$ & 46.5 \\
\hline $65+$ & 13.8 \\
\hline Female & 64.3 \\
\hline \multicolumn{2}{|l|}{ Education } \\
\hline High school or less & 5.9 \\
\hline Some college or associates degree & 22.2 \\
\hline Bachelor's degree & 31.9 \\
\hline Graduate or professional school & 40.0 \\
\hline \multicolumn{2}{|l|}{ Race/ethnicity } \\
\hline White, non-Hispanic/Latino & 87.9 \\
\hline Black, non-Hispanic/Latino & 5.0 \\
\hline Asian & 2.5 \\
\hline Hispanic or Latino & 1.6 \\
\hline Other race/ethnicity or mixed race & 3.1 \\
\hline \multicolumn{2}{|l|}{ Work in medical profession ${ }^{b}$} \\
\hline Respondent & 30.6 \\
\hline Someone in household & 15.0 \\
\hline Nobody & 58.1 \\
\hline \multicolumn{2}{|l|}{ Self-rated health } \\
\hline Excellent & 18.9 \\
\hline Very good & 45.3 \\
\hline Good & 28.3 \\
\hline Fair & 5.9 \\
\hline Poor & 1.6 \\
\hline Has children & 66.7 \\
\hline
\end{tabular}

${ }^{a}$ Median 54 years, range $18-82$ years.

${ }^{\mathrm{b}}$ Medical professional responses add up to more than $100 \%$ because participants could indicate that they and someone in their household worked in the medical profession.

genomics, indicating that it would influence their teaching or health care practice (e.g. 'As a physician, I wanted to understand what patients might present to me'; 'This is the future of medicine and I want to be a role model and influence others about its importance').

\section{Perceptions of Personal Genomics}

The vast majority of respondents did not endorse deterministic perspectives about genetics, indicating that they believed that illnesses are multifactorial and that their genomic information would not definitively determine whether or not they would get a disease (table 3). However, their beliefs about what type of risk information the study would provide were varied, with many endorsing inaccurate beliefs about the CPMC, such as that 
Table 2. Motivations to participate in the CPMC study $(\mathrm{n}=305)^{\mathrm{a}}$

\begin{tabular}{llll}
\hline & $\begin{array}{l}\text { Very important, } \\
\%\end{array}$ & $\begin{array}{l}\text { Somewhat important, } \\
\%\end{array}$ & $\begin{array}{l}\text { Not important, } \\
\%\end{array}$ \\
\hline Curiosity about my genes & 81.2 & 16.1 & 2.7 \\
Find out about diseases for which I am at risk & 78.4 & 19.9 & 1.7 \\
Find out what I can do to improve my health & 77.9 & 18.1 & 4.0 \\
Participate in research to help others & 56.2 & 38.5 & 5.4 \\
No cost to me to participate & 51.7 & 34.9 & 13.4 \\
Want information about risk of health conditions for & 46.8 & 20.1 & 10.0 \\
$\quad$ children and grandchildren & 37.7 & 16.7 & 45.7 \\
Interested in specific medical conditions & 29.8 & 33.6 & 3.1 \\
Interested in my ancestry & 3.2 & 2.1 & $95.8^{\mathrm{b}}$ \\
Adopted and want information about genetics & 0.7 & 97.3 \\
Everyone else at the session was enrolling & & 2.1 & \\
\hline
\end{tabular}

a Only those who answered that they chose to enroll in the CPMC $(\mathrm{n}=305)$ were asked about their motivations.

b Not important for the 'adopted' category includes 258 individuals (90.5\%) who indicated 'not applicable'.

Table 3. Perceptions and misperceptions of personalized genomics $(\mathrm{n}=336)^{\mathrm{a}}$

Agreeing or strongly agreeing, \%

A person can have a gene for a condition (like diabetes or cancer) and not develop that condition

95.1

Common health conditions are caused by genes in combination with lifestyle and environmental factors 96.6

The information in the CPMC will tell me definitely whether or not I will get a disease

9.0

Endorsing, \%

The CPMC will tell me about my risk for

$\begin{array}{lr}\text { All diseases (inaccurate) } & 12.0\end{array}$

$\begin{array}{lr}\text { All genetic diseases (inaccurate) } & 30.7\end{array}$

$\begin{array}{lr}\text { Cystic fibrosis (inaccurate) } & 13.9\end{array}$

Diabetes (accurate) $\quad 82.6$

$\begin{array}{lr}\text { Having a child with a birth defect (inaccurate) } & 10.4\end{array}$

\begin{tabular}{lr} 
Side effects from drugs (accurate) & 71.5 \\
\hline
\end{tabular}

$\begin{array}{lr}\text { Risk from infection (inaccurate) } & 16.5\end{array}$

a All respondents who indicated they had attended an enrollment event $(n=336)$ were asked their perceptions of personalized genomics, regardless of whether they decided to enroll in the CPMC.

they would learn about their risk for cystic fibrosis (13.9\%) or birth defects among their offspring (10.4\%).

Consistent with their stated motivations to pursue personal genomics, most respondents believed that the study would provide them with health-related benefits (behavior change and personalized treatment plans) as well as the benefit of helping researchers (table 4). Some expressed unrealistic expectations, with $13 \%$ of respondents believing that one benefit of the study would be to gain access to gene therapy. Concern about risks was modest, and $31 \%$ believed there were no risks at all. The most commonly perceived risks of the study were 'worry' (30\%) and learning about a disease risk they did not want to know about (29\%); the latter was reported in spite of 
Table 4. Perceptions of risks and benefits of the CPMC $(n=305)^{\mathrm{a}}$

Agreeing or strongly agreeing, \%

$\begin{array}{lr}\text { Perceptions of benefits of CPMC } & \\ \text { Help researchers learn about genes and disease } & 94.3 \\ \text { Results will help me change my behaviors and reduce risk } & 87.5 \\ \text { Seek medical attention and reduce disease risk } & 81.4 \\ \text { Results will tell me what medications to avoid } & 64.9 \\ \text { Learn about risk of disease for children } & 46.6 \\ \text { Results will tell me what medications to take } & 25.1 \\ \text { I can have gene therapy to reduce my risk } & 12.9 \\ \text { There are no benefits } & 3.2 \\ \text { Perceptions of risks of CPMC } & 31.7 \\ \text { There are no risks } & 30.4 \\ \text { Results may make me worry } & 28.6 \\ \text { I will learn about risks that I did not want to know about } & 18.9 \\ \text { I may not be able to get insurance if results get out } & 14.9 \\ \text { I will learn about risks I can do nothing about } & 5.4 \\ \text { I could lose my job if the results get out } & \end{array}$

a Only those respondents who enrolled in the CPMC $(n=305)$ were asked their perceptions of the risks and benefits of the study.

the CPMC study design, described in the enrollment session, that specifically allows participants to select not to view any particular risk information (table 4 ).

Overall, 32\% of respondents stated one or more misperception of personal genomics (that a benefit would be gene therapy, that they would learn about their risk for all diseases or all genetic diseases, or that they would find out about potential birth defects or cystic fibrosis). In a multivariate logistic regression model assessing predictors of misperceptions (controlling for gender, educational attainment, white vs. nonwhite race, health status, and having children), people older than 55 were less likely $(\mathrm{OR}=0.52, \mathrm{CI}=0.30-0.93)$, while people not working in the health profession were more likely $(\mathrm{OR}=1.72, \mathrm{CI}=$ $1.00-2.97)$ to have misperceptions.

\section{Intentions to Share Results}

Nearly all respondents (91.7\%) stated that they were likely to share their results with their physicians; $57.7 \%$ stated that they were very likely to do so. Among the 25 individuals $(8.3 \%)$ who indicated they were unlikely to share, the most common reasons were that they did not think their doctor would know how to interpret the results $(n=9)$ or they were concerned about privacy $(n=8)$. Of the 279 respondents who intended to share their results, only $25.8 \%$ indicated they would share so that their physicians could explain their results to them. In con- trast, $67.5 \%$ wanted their physician to tell them how to improve their health based on their genes, $79.0 \%$ wanted their physician to prescribe the best medicine for them based on their genes and $71.0 \%$ believed their genomic risk information should be a part of their medical record. Among individuals who wrote in some other reason for sharing $(\mathrm{n}=31), 6$ planned to share in order to make their physician more aware of personal genomics. As one respondent stated, 'I'd like my doctor to realize that genomic medicine is already starting to be useful.'

\section{Discussion}

This study of 'early adopters' of personal genomics reveals several important findings with implications for future public interest in and use of personal genomics. These early adopters want genetic risk information in order to improve their health, and they intend to do so in close consultation with their physicians. This finding is consistent with McGuire et al.'s [19] observation that potential consumers' main motivations for accessing DTC genetic testing services was for health-related uses and their own curiosity. In addition, we find that the vast majority of respondents (over 90\%) intend to share their genomic risk information with their health care providers. There are many factors that could explain these high 
reported intentions to share, including encouragement to share results with health care providers during the CPMC enrollment presentation, perceived health implications of the results and hope that results could be used in medical management. While this study was not designed to assess whether participants do in fact follow through on their intentions to share, preliminary data from the CPMC suggest that a smaller proportion of participants actually go on to share their results: $15 \%$ (n = 245) had shared their data an average of 6 months after viewing their results, with an additional $50 \%$ still intending to share [26]. Similarly, Kaufman et al. [23] found that $29 \%$ had shared results from a commercial DTC genetic testing service with their health care providers, while $18 \%$ intended to do so, and Bloss et al. [27] found that $26.5 \%$ had shared about 5 months after DTC testing. Of note, while McGuire et al. [19] observed that most people who would consider using DTC services would ask their providers for help interpreting their results, respondents in the current study want to involve their physicians not for interpretation assistance but to obtain specific medical advice. This discrepancy may relate to the familiarity that this population had with personalized medicine (78\% reported having heard about personalized medicine), the high number of participants themselves or family members working in the health care professions $(40 \%)$, or the availability of genetic counseling (at no charge) through the CPMC.

The enthusiasm of respondents to interact with their physicians raises important questions about the public health impact of personal genomics. As others have speculated, health care providers are unlikely to be sufficiently prepared to provide such guidance to their patients that the patients seem to expect [14]. Moreover, study participants' intentions to seek medical advice suggests that early adopters of personal genomics (including the DTC context or through other research studies) may pursue follow-up testing and screening, posing costs to the health care system [28] and raising the possibility of harm if individuals experience side effects from unnecessary or unwarranted medical care [6]. In their recent policy statement, the European Society of Human Genetics argued that, because of these concerns of undue burden on primary care physicians and public health resources and the threat of negative consequences on patient's health, only tests that meet clinical utility and quality criteria should be introduced into clinical practice [29]. Thus, it is critically important to follow early adopters' utilization of general medical services after testing, to evaluate what type of regulatory guidance will best promote public health. However, it is worth noting that, as other research has suggested, respondents' stated intentions often do not translate into actions, so additional follow-up research is needed $[19,30]$. For instance, in the first published longitudinal study of the impact of DTC testing, researchers found no impact of test results on utilization of screening tests, but they did find an impact on intentions to receive screening tests, many of which are not appropriate for asymptomatic individuals [27].

While respondents expressed great enthusiasm about the potential benefits of personal genomics for their health, some expressed potentially unrealistic expectations and had misunderstandings about genomic profiling for common complex diseases. Those not working in the health care field were particularly susceptible to these misunderstandings. Such high public expectations of genetics have been observed in other studies [31-33]. The misperceptions observed in this relatively highly educated study population, particularly conflating testing for common complex diseases with that for single-gene disorders and reproductive genetics, suggests that members of the public will not easily distinguish between the 'old' paradigm of genetic disorders and the 'new' paradigm of genomic risk information for chronic complex diseases [34].

Although respondents exhibited some misunderstanding about personal genomics testing and its benefits, the majority of respondents did not endorse deterministic attitudes about the role of genetics in influencing health. This finding is consistent with other empirical work showing that people exhibit a sophisticated awareness that health is produced by both behaviors and genetic inheritance $[24,35]$. In fact, recent evidence from a population-based survey of British adults reveals that people who recognize the influence of genetics within chronic disease are more, not less likely to also recognize the role of lifestyles [36]. Given growing evidence of the public's ability to appreciate the simultaneous causal roles of genetics, behaviors and environment, future behavioral and psychosocial research might expand beyond genetic fatalism to address other important public health outcomes of genetic information [13] and to explore the circumstances under which people consider these interactive causal factors to be more or less important to their health [35]. 


\section{Limitations and Future Directions}

These results must be interpreted in light of several limitations of the sample and study design. Study participants are not representative of the general population. They are highly educated, with relatively few racial or ethnic minorities, many health care professionals and all (as a result of the CPMC study design) had Internet access. Users of other personal genomic services have been similarly described as having a high educational attainment [22]. Indeed, this is not surprising, since high educational status and high socioeconomic status are characteristics of early adopters in Rogers' theoretical model [17]. Other researchers have also found that African Americans are less likely to participate in personal genomics research, even when they have access to care and are specifically sampled [37]. While the study sample demographics may reflect those who are currently interested in personal genomics and who actively seek it out (albeit at no cost to them, unlike in the DTC context), these findings cannot be extended to the general population that may encounter personal genomics either in retail stores or in a physician's office in years to come. In addition, because nearly all interested participants ended up enrolling in the CPMC study, comparisons between those who decided to enroll and those who were interested but did not enroll were not possible. Alternative study designs are required to make such comparisons [24].

Overall, these results reveal a group of people who are particularly eager for personalized risk information to influence their health and health care. However, much more behavioral research is needed to understand how this population (and other similar groups of early adopt- ers) will actually respond to and act upon risk information when they receive it. Interviews are currently being conducted with CPMC participants after they receive their results to assess participants' understanding of and response to their results. Important research questions for the future include assessing how people who receive genomic risk information will integrate and assign priority to risk information of multiple types (i.e. lifestyle, genetic and family history) and how they will respond to changing genomic risk estimates over time as new variants are identified and replicated [38]. Moreover, in order to evaluate concerns about the potential for unnecessary medical care among users of these services [28], research must ascertain whether intentions to involve physicians match actual behaviors, whether physicians will recommend particular medical treatments or screening, and the cost of and likely adherence to those recommendations. Finally, research must address the best modes of pre-test education so that consumers have an adequate understanding of the risks, benefits and limitations of this type of novel testing as it becomes integrated into medical care.

\section{Acknowledgements}

This study was supported by funding from the National $\mathrm{Hu}$ man Genome Research Institute, National Institutes of Health (1RC1HG005369-01 and 1-P50HG004487-01). The Coriell Personalized Medicine Collaborative was funded by the William G. Rohrer Foundation and the RNR Foundation. S. Gollust was supported by the Robert Wood Johnson Foundation Health \& Society Scholars program during the time of this study. We gratefully acknowledge the research assistance of Shimrit Keddem, MPH.

\section{References}

1 Burke W, Psaty BM: Personalized medicine in the era of genomics. JAMA 2007;298: $1682-1684$.

2 Gollust SE, Wilfond BS, Hull SC: Direct-toconsumer sales of genetic services on the internet. Genet Med 2003;5:332-337.

-3 Evans JP, Green RC: Direct to consumer genetic testing: avoiding a culture war. Genet Med 2009;11:568-569.

4 Gulcher J, Stefansson K: Genetic risk information for common diseases may indeed be already useful for prevention and early detection. Eur J Clin Invest 2010;40:56-63.

$\checkmark 5$ Offit K: Genomic profiles for disease risk: predictive or premature? JAMA 2008;299: 1353-1355.
6 Ransohoff DF, Khoury MJ: Personal genomics: information can be harmful. Eur J Clin Invest 2010;40:64-68.

7 Caulfield T, Ries NM, Ray PN, Shuman C, Wilson B: Direct-to-consumer genetic testing: good, bad or benign? Clin Genet 2010; 77:101-105.

${ }_{8} \mathrm{Ng}$ PC, Murray SS, Levy S, Venter JC: An agenda for personalized medicine. Nature 2009;461:724-726.

-9 Khoury MJ, McBride CM, Schully SD, Ioannidis JP, Feero WG, Janssens AC, Gwinn M, Simons-Morton DG, Bernhardt JM, Cargill M, Chanock SJ, Church GM, Coates RJ, Collins FS, Croyle RT, Davis BR, Downing GJ, Duross A, Friedman S, Gail MH, Ginsburg
GS, Green RC, Greene MH, Greenland P, Gulcher JR, Hsu A, Hudson KL, Kardia SL, Kimmel PL, Lauer MS, Miller AM, Offit K, Ransohoff DF, Roberts JS, Rasooly RS, Stefansson K, Terry SF, Teutsch SM, Trepanier A, Wanke KL, Witte JS, Xu J; Centers for Disease Control and Prevention: The scientific foundation for personal genomics: recommendations from a National Institutes of Health-Centers for Disease Control and Prevention multidisciplinary workshop. Genet Med 2009;11:559-567.

10 McBride CM, Bowen D, Brody LC, Condit CM, Croyle RT, Gwinn M, Khoury MJ, Koehly LM, Korf BR, Marteau TM, McLeroy K, Patrick K, Valente TW: Future health ap- 
plications of genomics: priorities for communication, behavioral, and social sciences research. Am J Prev Med 2010;38:556-565.

- 11 Prainsack B, Reardon J, Hindmarsh R, Gottweis $H$, Naue $U$, Lunshof JE: Personal genomes: misdirected precaution. Nature 2008;456:34-35.

12 Kraft P, Hunter DJ: Genetic risk prediction - are we there yet? N Engl J Med 2009; 360:1701-1703.

13 McBride CM, Koehly LM, Sanderson SC, Kaphingst KA: The behavioral response to personalized genetic information: will genetic risk profiles motivate individuals and families to choose more healthful behaviors? Annu Rev Public Health 2010;31:89-103.

14 Guttmacher AE, Porteous ME, McInerney JD: Educating health-care professionals about genetics and genomics. Nat Rev Genet 2007;8:151-157.

15 Hogarth S, Javitt G, Melzer D: The current landscape for direct-to-consumer genetic testing: legal, ethical, and policy issues. Annu Rev Genomics Hum Genet 2008;9: 161-182.

16 Kolor K, Liu T, St Pierre J, Khoury MJ: Health care provider and consumer awareness, perceptions, and use of direct-to-consumer personal genomic tests, United States, 2008. Genet Med 2009;11:595.

17 Rogers EM: Diffusion of Innovations. New York, The Free Press, 1995.

18 Berwick DM: Disseminating innovations in health care. JAMA 2003;289:1969-1975.

-19 McGuire AL, Diaz CM, Wang T, Hilsenbeck SG: Social networkers' attitudes toward direct-to-consumer personal genome testing. Am J Bioeth 2009;9:3-10.

-20 O’Daniel JM, Haga SB, Willard HF: Considerations for the impact of personal genome information: a study of genomic profiling among genetics and genomics professionals. J Genet Couns 2010;19:387-401.
21 McGowan ML, Fishman JR, Lambrix MA: Personal genomics and individual identities: motivations and moral imperatives of early users. New Genet Soc 2010;29:261-290.

22 Bloss CS, Ornowski L, Silver E, Cargill M, Vanier V, Schork NJ, Topol EJ: Consumer perceptions of direct-to-consumer personalized genomic risk assessments. Genet Med 2010;12:556-566.

23 Kaufman D, Murphy Bollinger J, Devaney S, Scott J: Direct from consumers: a survey of 1,048 customers of three direct-to-consumer personal genomic testing companies about motivations, attitudes, and responses to testing. Abstract 60th Annual Meeting ASHG, Washington DC, November 2010.

24 McBride CM, Alford SH, Reid RJ, Larson EB, Baxevanis AD, Brody LC: Characteristics of users of online personalized genomic risk assessments: implications for physician-patient interactions. Genet Med 2009;11:582587.

25 Keller MA, Gordon ES, Stack CB, Garani N, Sill CJ, Schmidlen TJ, Mintzer J, Pallies J, Gerry NP, Christman MF: Coriell personalized medicine collaborative: a prospective study of the utility of personalized medicine. Per Med 2010;7:301-317.

26 Gordon ES, Stack CB, Gharani N, Schmidlen TJ, Christman MF, Keller MA: Perceived risk, anxiety and sharing behavior in response to personalized risk information in a Cohort study. Abstract 60th Annual Meeting ASHG, Washington DC, November 2010.

27 Bloss CS, Schork NJ, Topol EJ: Effect of direct-to-consumer genomewide profiling to assess disease risk. N Engl J Med 2011;364: 524-534.

28 McGuire AL, Burke W: An unwelcome side effect of direct-to-consumer personal genome testing: raiding the medical commons. JAMA 2008;300:2669-2671.

29 European Society of Human Genetics: Statement of the ESHG on direct-to-consumer genetic testing for health-related purposes. Eur J Hum Genet 2010;18:1271-1273.
30 Sanderson SC, O’Neill SC, Bastian LA, Bepler G, McBride CM: What can interest tell us about uptake of genetic testing? Intention and behavior amongst smokers related to patients with lung cancer. Public Health Genomics 2010;13:116-124.

31 Henderson G, Garrett J, Bussey-Jones J, Moloney ME, Blumenthal C, Corbie-Smith G: Great expectations: views of genetic research participants regarding current and future genetic studies. Genet Med 2008;10:193200

32 Rogausch A, Prause D, Schallenberg A, Brockmoller J, Himmel W: Patients' and physicians' perspectives on pharmacogenetic testing. Pharmacogenomics 2006;7:49-59.

33 Hahn S, Letvak S, Powell K, Christianson C, Wallace D, Speer M, Lietz P, Blanton S, Vance J, Pericak-Vance M, Henrich VC; The Genomedical Connection: A community's awareness and perceptions of genomic medicine. Public Health Genomics 2010;13:63-71.

34 Eng C, Sharp RR: Bioethical and clinical dilemmas of direct-to-consumer personal genomic testing: the problem of misattributed equivalence. Sci Transl Med 2010;2:17cm5.

35 Condit CM: Public understandings of genetics and health. Clin Genet 2010;77:1-9.

36 Sanderson SC, Waller J, Humphries SE, Wardle J: Public awareness of genetic influence on chronic disease risk: are genetic and lifestyle causal beliefs compatible? Public Health Genomics DOI: 10.1159/000294280.

- 37 Alford SH, McBride CM, Reid R, Larson E, Baxevanis AD, Brody LC: Participation in genetic testing research varies by social group. Public Health Genomics 2011;14:8593.

38 Mihaescu R, van Hoek M, Sijbrands EJ, Uitterlinden AG, Witteman JC, Hofman A, van Duijn CM, Janssens AC: Evaluation of risk prediction updates from commercial genome-wide scans. Genet Med 2009;11:588594. 